\title{
ARTICLE
}

\section{Impact of caspase-1/11, -3, -7, or IL-1 $\beta /$ IL-18 deficiency on rabies virus-induced macrophage cell death and onset of disease}

\author{
E Kip ${ }^{1,2,3,6}$, F Nazé ${ }^{1,6}$, V Suin ${ }^{1}$, T Vanden Berghe ${ }^{3,4}$, A Francart ${ }^{1}$, S Lamoral ${ }^{1}$, P Vandenabeele ${ }^{3,4}$, R Beyaert ${ }^{2,3,7}$, S Van Gucht ${ }^{1,5,7}$ and \\ M Kalai ${ }^{1,7,8}$
}

Rabies virus is a highly neurovirulent RNA virus, which causes about 59000 deaths in humans each year. Previously, we described macrophage cytotoxicity upon infection with rabies virus. Here we examined the type of cell death and the role of specific caspases in cell death and disease development upon infection with two laboratory strains of rabies virus: Challenge Virus Standard strain-11 (CVS-11) is highly neurotropic and lethal for mice, while the attenuated Evelyn-Rotnycki-Abelseth (ERA) strain has a broader cell tropism, is non-lethal and has been used as an oral vaccine for animals. Infection of Mf4/4 macrophages with both strains led to caspase- 1 activation and IL-1 $\beta$ and IL-18 production, as well as activation of caspases- $3,-7,-8$, and -9 . Moreover, absence of caspase3 , but not of caspase-1 and -11 or -7 , partially inhibited virus-induced cell death of bone marrow-derived macrophages. Intranasal inoculation with CVS-11 of mice deficient for either caspase-1 and -11 or -7 or both IL-1 $\beta$ and IL-18 led to general brain infection and lethal disease similar to wild-type mice. Deficiency of caspase-3, on the other hand, significantly delayed the onset of disease, but did not prevent final lethal outcome. Interestingly, deficiency of caspase-1/11, the key executioner of pyroptosis, aggravated disease severity caused by ERA virus, whereas wild-type mice or mice deficient for either caspase-3, -7 , or both IL-1 $\beta$ and IL-18 presented the typical mild symptoms associated with ERA virus. In conclusion, rabies virus infection of macrophages induces caspase-1- and caspase-3-dependent cell death. In vivo caspase-1/11 and caspase-3 differently affect disease development in response to infection with the attenuated ERA strain or the virulent CVS-11 strain, respectively. Inflammatory caspases seem to control attenuated rabies virus infection, while caspase- 3 aggravates virulent rabies virus infection.

Cell Death Discovery (2017) 3, 17012; doi:10.1038/cddiscovery.2017.12; published online 6 March 2017

\section{INTRODUCTION}

Rabies virus is a negative single-stranded RNA virus belonging to the Genus Lyssavirus, Familia Rhabdoviridae. It consists of a helicoidal nucleocapsid, surrounded by a phospholipid membrane, which contains an external glycoprotein $(G)$ and an internal matrix protein (M). ${ }^{1}$ Rabies virus is a primary encephalotropic virus, which causes significant mortality worldwide and remains an important public health problem. Rabies causes about 59000 human deaths each year. ${ }^{2}$ Neurons and muscle cells have long been recognized as the typical target cells of rabies virus, but we showed that macrophages can also be infected productively and transmit the virus upon cell transfer in vivo. ${ }^{3}$ The neurovirulence of rabies virus is often studied in rodent models using fixed laboratory strains with different degrees of pathogenicity. The Challenge Virus Standard strain-11 (CVS-11) is a fixed laboratory virus that shows a strong neurotropism in mice and causes fatal acute encephalitis. ${ }^{4,5}$ Evelyn-Rotnycki-Abelseth virus (ERA) is a highly attenuated laboratory strain that was adapted to replicate in non-neuronal cells ${ }^{6}$ and induces an abortive, non-lethal infection of the nervous system. ERA triggers an efficient immune response and has been used as a live vaccine for immunization of wildlife. ${ }^{7}$ Preventive therapy for rabies is efficacious, but there is no effective therapy for patients with symptoms. A better understanding of basic mechanisms underlying the pathogenesis of rabies encephalitis, including cell death processes, is needed. ${ }^{8}$

Programmed cell death is a process by which cells participate in their own death in a regulated manner. Viral infections often elicit programmed cell death as part of the host defense system to cut virus infection and it is not surprising that this is targeted by pathogen-encoded cell death suppressors to modulate host cell death pathways., ${ }^{9,10}$ Apoptosis and pyroptosis constitute major cell death modes for elimination of infected cells and are characterized by distinct signaling pathways and morphologic changes.

Apoptosis is a non-lytic and caspase-dependent host defense pathway triggered through cell-intrinsic and cell-extrinsic factors. The extrinsic pathway is based on activation of cell death receptors, whereas the intrinsic pathway occurs through the mitochondria. Both pathways lead to activation of effector

\footnotetext{
${ }^{1}$ National Reference Centre of Rabies, Viral Diseases, Communicable and Infectious Diseases, Scientific Institute of Public Health (WIV-ISP), Brussels, Belgium; ${ }^{2}$ Inflammation Research Center, Unit of Molecular Signal Transduction in Inflammation, VIB, Ghent, Belgium; ${ }^{3}$ Department of Biomedical Molecular Biology, Ghent University, Ghent, Belgium; ${ }^{4}$ Inflammation Research Center, Molecular Signalling and Cell Death Unit, VIB, Ghent, Belgium and ${ }^{5}$ Laboratory of Virology, Department of Virology, Parasitology and Immunology, Faculty of Veterinary Medicine, Ghent University, Ghent, Belgium.

Correspondence: S Van Gucht (steven.vangucht@wiv-isp.be)

${ }^{6}$ These authors contributed equally to this work.

${ }^{7}$ These authors share senior authorship.

${ }^{8}$ Current address: Clinical Laboratory Sciences (CLS), Clinical Evidence Generation (CEG) - R\&D, GSK Vaccines, Rixensart, Belgium.

Received 17 January 2017; accepted 27 January 2017; Edited by A Rufini.
} 
caspases, which ultimately form the apoptosome. There are 13 members of the caspase family. Caspases involved in apoptosis include caspase-2, $-8,-9,-10$, and -12 (the initiator caspases) and caspase- $3,-6,-7$, and -14 (the effector caspases). ${ }^{9}$ Rabies virus has been shown to induce apoptosis and caspase activation in infected cells, ${ }^{11-13}$ but the role of apoptosis in pathogenicity is controversial. Apoptotic neurons were detected in the brain of mice upon intracranial inoculation of virulent rabies virus. ${ }^{14-16}$ Jackson et al. ${ }^{17}$ suggest that there is an inverse relationship between pathogenicity and neuronal apoptosis and that neuronal apoptosis does not contribute to pathogenicity in human rabies encephalitis, ${ }^{18}$ even if apoptosis is detected in brains of human patients. ${ }^{19}$ Others reported that rabies virus can infect mouse and human lymphocytes and induce their apoptosis ${ }^{20,21}$ or suggested that $\mathrm{T}$ lymphocytes invading the brain undergo apoptosis, which may promote the neuroinvasion and spread of virulent rabies virus. ${ }^{22} \mathrm{~A}$ more recent study compared different strains of rabies virus (virulent street virus CNM11 and attenuated virus CTN) and detected active caspase- 3 in the brain of mice infected with attenuated or virulent rabies virus. ${ }^{23} \mathrm{~A}$ higher rate of apoptosis was detected in brains of mice infected with the attenuated virus, with the location of apoptosis depending on the strain. Apoptosis is thus clearly induced during rabies infection but its exact contribution in rabies pathogenicity with either attenuated or virulent rabies virus remains unclear.

Pyroptosis is an inflammasome-dependent cell death mode executed following activation of inflammatory caspases caspase- 1 or mouse caspase-11. The inflammatory caspases in humans include caspase-1, caspase-4, caspase-5, and caspase- 12 . In mice, caspase- 11 is the ortholog of human caspase- 4 and caspase- $5 .^{24}$ Pyroptosis releases intracellular contents, like necrosis, but also induces nuclear condensation and DNA fragmentation, like apoptosis. $^{25}$ Canonical inflammasome activation results in procaspase- 1 cleavage and activation. Distinct inflammasomes can be formed depending on the infectious agent and to date, five receptors have been established to form an inflammasome named NLRP1, NLRP3, NLRC4, AIM2, and PYRIN. ${ }^{24,26}$ Activatedcaspase- 1 is responsible for the proteolytic maturation of the inflammatory cytokines pro-IL-1 $\beta$ and pro-IL-18 in myeloid cells and neurons, which makes pyroptosis a proinflammatory cell death mode. On the other hand, the activation of a noncanonical inflammasome results in activation of procaspase-11. Caspase-11 is required for IL-1 $\beta$ release and pyroptosis in response to Gramnegative bacteria and cytosolic LPS. $^{27,28}$ The canonical and noncanonical inflammasomes regulate release of IL-1a and IL-1 $\beta$ and both caspase- 1 and caspase- 11 can induce pyroptosis, but only caspase- 1 processes preforms of IL-1 $\beta$ and IL-18 into active forms, which are secreted. ${ }^{28}$ Many RNA viruses, such as encephalomyocarditis virus, vesicular stomatitis virus, measles virus, hepatitis C virus, and influenza virus, have been shown to activate the NLRP3 inflammasome. ${ }^{29}$ Rabies virus was shown to be recognized by the NLRP3 inflammasome and to activate IL-1 $\beta$ release in murine dendritic cells. ${ }^{29,30}$ In that study, IL-1R-deficient mice showed an increase in rabies virus pathogenicity, but the exact contribution of inflammasome-mediated pyroptosis and IL-1 $\beta$ release in rabies pathogenicity is still unknown.

It is unclear what is the role of different caspases in rabies virusinduced cytotoxicity and whether cell death is detrimental, by contributing to pathogenicity, or beneficial, by limiting virus spread, for the host. ${ }^{10}$ In this study, we used specific caspasedeficient mice and macrophages to investigate the role of different caspases and cell death pathways in rabies virus infection and pathogenesis. First, we examined the type of cell death and pathways that are activated by rabies virus in an in vitro cell model. The spleen macrophage-derived Mf4/4 cell line was initially used because previous studies showed these cells are highly susceptible for cell death upon infection with rabies virus. The association between infection, virus production, and cell viability was examined and compared for two rabies virus strains with contrasting pathogenic properties, CVS-11 and ERA. Western-blot and immunoprecipitation were applied to study the activation of apoptotic and pyroptotic pathways in Mf4/4 macrophages. The impact of caspase- $1 / 11,-3$, or -7 deficiency on virus-induced cell death was further studied in bone marrow-derived macrophages (BMDM). Finally, we examined the impact of a deficiency in caspase-1/11, -3, -7, or IL- $1 \beta / \mathrm{IL}-18$ on the virological and clinical outcome of rabies virus infection in mice.

\section{RESULTS}

ERA and CVS-11 cause cell death and activation of caspases in Mf4/4 macrophages

We have shown before that rabies virus can infect macrophages in vitro, but cell death signaling pathways in that type of cell and their impact on the development of disease were not yet explored. Here we compared the cytotoxicity of attenuated ERA and virulent CVS-11 strains toward the cell line Mf4/4. Therefore, we monitored the production of infectious rabies virus particles and cell viability up to $48 \mathrm{~h}$ post inoculation (hpi) of the cells with the virus.

Infection of Mf4/4 cells with CVS-11 yielded $10^{3.5} \mathrm{TCID}_{50} / \mathrm{ml}$ infectious particles, which was 10-15-fold less productive than with the attenuated ERA strain (Figure 1a). The rate of infected cells was determined using fluorescence microscopy imaging of cells stained with an antibody directed to the viral $\mathrm{N}$ protein (Figures $1 \mathrm{c}$ and $\mathrm{d}$ ). The majority of the ERA virus-inoculated Mf4/4 cells were infected, since at least $68 \%$ expressed the viral $\mathrm{N}$ protein. However, only $9 \%$ of the macrophages inoculated with the CVS-11 were fluorescent for viral $\mathrm{N}$ protein (Figures $1 \mathrm{c}$ and $\mathrm{d}$ ). The percentage of infected cells and production of infectious rabies virus particles correlated with the rate of cell death, as assessed by measuring cell adherence. A strong decrease of macrophage cell adherence was observed upon infection with ERA (Figure $1 \mathrm{~b}$ ). Only $51 \%$ of Mf $4 / 4$ remained adherent $48 \mathrm{hpi}$, which is significantly less than with the virulent strain $(88 \%)$ $(P<0.001$, two-way ANOVA).

In parallel, Mf $4 / 4$ cell death induced by rabies virus was analysed by the binding of the intracellular green fluorescent caspase inhibitor (FLICA) to active caspases (Figures $1 \mathrm{e}$ and $\mathrm{f}$ ). Caspase activation was seen in $94,6 \%$ of ERA-inoculated cells, while infection with CVS-11 induced activation of caspases only in $8,8 \%$ of the cells, which corresponds with the lower infection rate of CVS-11 (Figures 1e and f). Mock-infected macrophages showed no fluorescence in the presence of FLICA. These data suggest that caspase activation is involved in rabies virus-induced Mf $4 / 4$ cell death and that ERA infects and replicates more efficiently in macrophages than CVS-11. Moreover, both strains induce cell death, ${ }^{3}$ but since more macrophages become infected with ERA than with CVS-11, caspase activation is more obvious with the former.

Activation of signaling pathways for apoptosis and pyroptosis in rabies virus-infected $\mathrm{Mf} 4 / 4$

We analysed two forms of cell death requiring caspase activation, namely apoptosis and pyroptosis, in rabies virus-infected macrophages. Since Mf4/4 are highly susceptible to infection with ERA, we analysed lysates of ERA virus-infected Mf4/4 by western blotting at 24 and 48 hpi using antibodies against different caspases and the pro-apoptotic peptide truncated Bid (tBid). Specific antibodies against active IL-1 $\beta$ and caspase- 1 were used as pyroptosis markers.

Analysis of cell lysates of ERA virus-infected Mf4/4 indicated that cleaved active caspase- $3,-7$, and -9 and tBid were detected $24 \mathrm{hpi}$, 


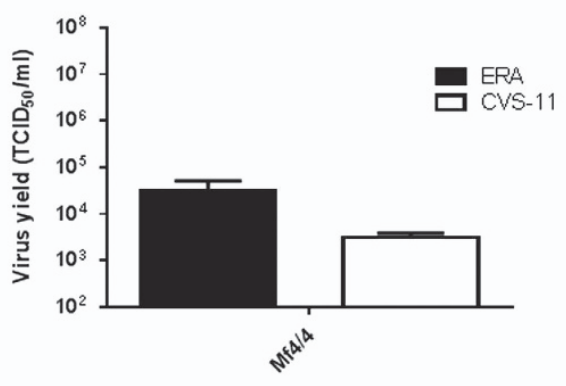

C

Hoechst
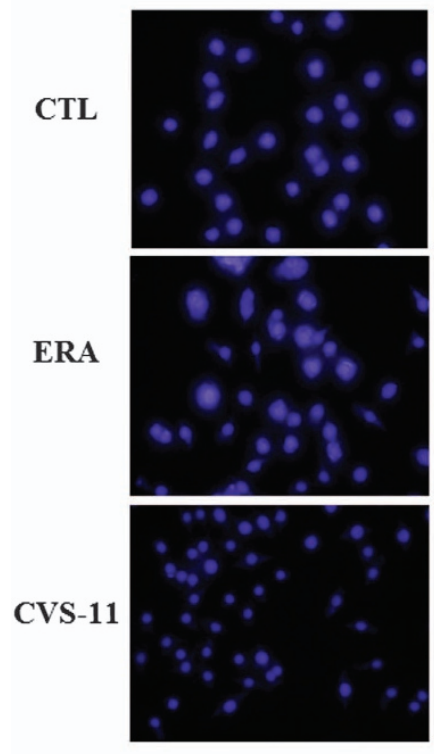

Anti-N rabies FITC
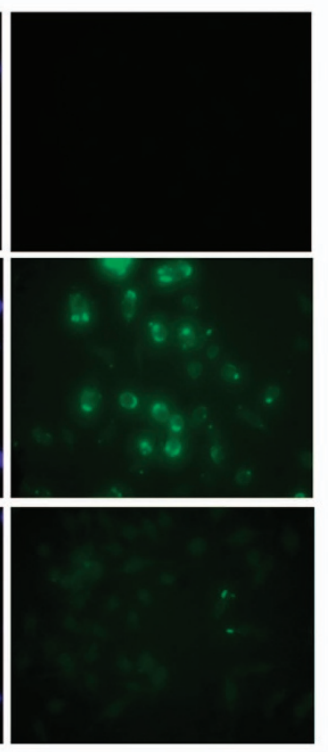

d

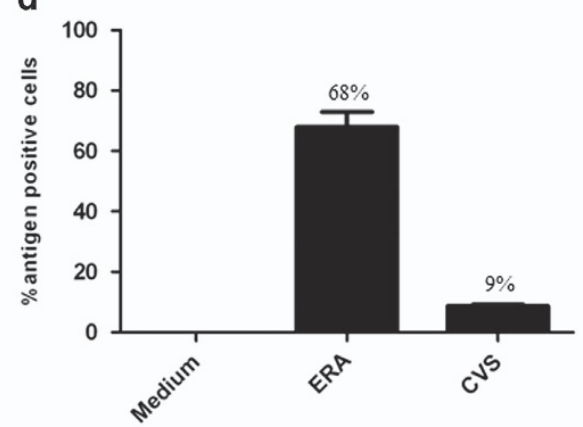

\section{Cell death}

b

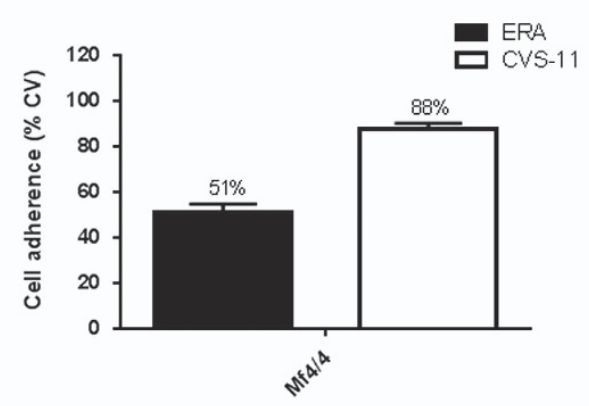

e
Hoechst
FLICA
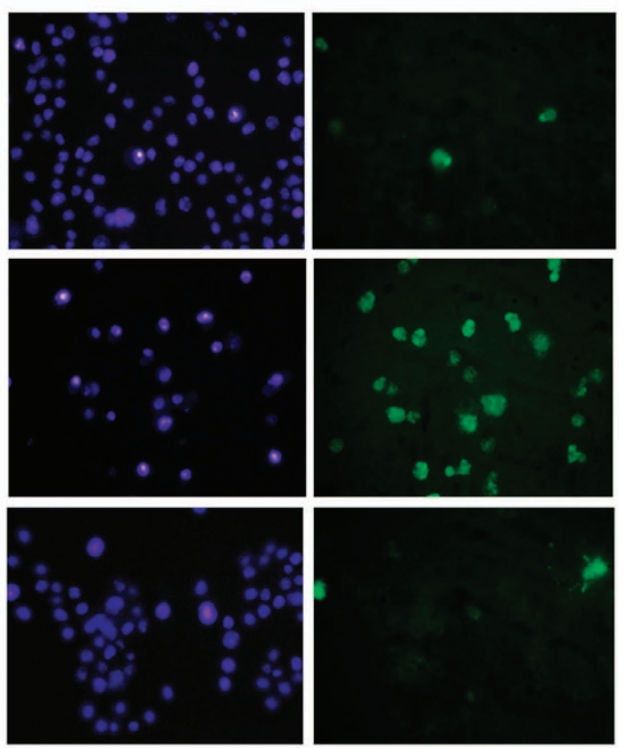

f

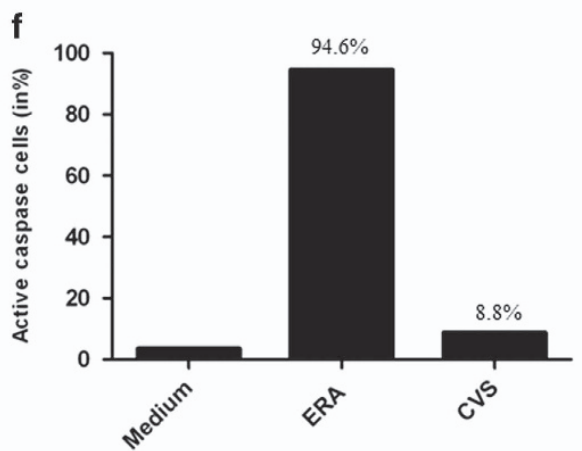

Figure 1. Comparison between viral load and cell death in Mf4/4 cells following infection with ERA or CVS-11 rabies virus strains. (a) Virus titer was measured at $48 \mathrm{hpi}$ using titration in BHK-21 cells. (b) Cellular viability was determined using the crystal violet staining method to measure the viable adherent cells as a percentage compared to uninfected control cells. Data are representative of at least five independent experiments and are presented as mean values \pm S.E.M. (c) Fluorescence microscopy imaging of viral $\mathrm{N}$ protein to measure the number of infected Mf4/4. Cells were stained with Hoechst (left panel) and FITC-labeled anti-rabies virus nucleocapsid antibody (right panel). (d) The percentage of antigen-positive cells is expressed by: (number of FITC-anti-N cells/numbers of Hoechst-positive cells) $\times 100$. (e) Analysis of caspase activity in infected Mf4/4 cells at $48 \mathrm{~h}$ post virus inoculation. Cells were stained with Hoechst (left panel) and with the green fluorescent caspases inhibitor (FLICA) that covalently binds to the active caspases (right panel). (f) The percentage of cells with active caspases is expressed by: (number of FLICA-positive cells/number of Hoechst-positive cells) $\times 100$.

whereas proteolytic cleavage of initiator caspase- 8 and the $20 \mathrm{kDa}$ fragment of cleaved and active caspase- 1 were detected at $48 \mathrm{hpi}$ (Figure 2). However, the $15 \mathrm{kDa}$ fragment corresponding to the active mature form of IL-1 $\beta$ could be immunoprecipitated from the culture supernatant of infected Mf4/4 already at $24 \mathrm{hpi}$. The cleavage of inactive $31 \mathrm{kDa}$ precursor IL-1 $\beta$ to the active mature cytokine requires active caspase- 1 , which suggests that caspase- 1 was already active at $24 \mathrm{hpi}$. These observations indicate that 

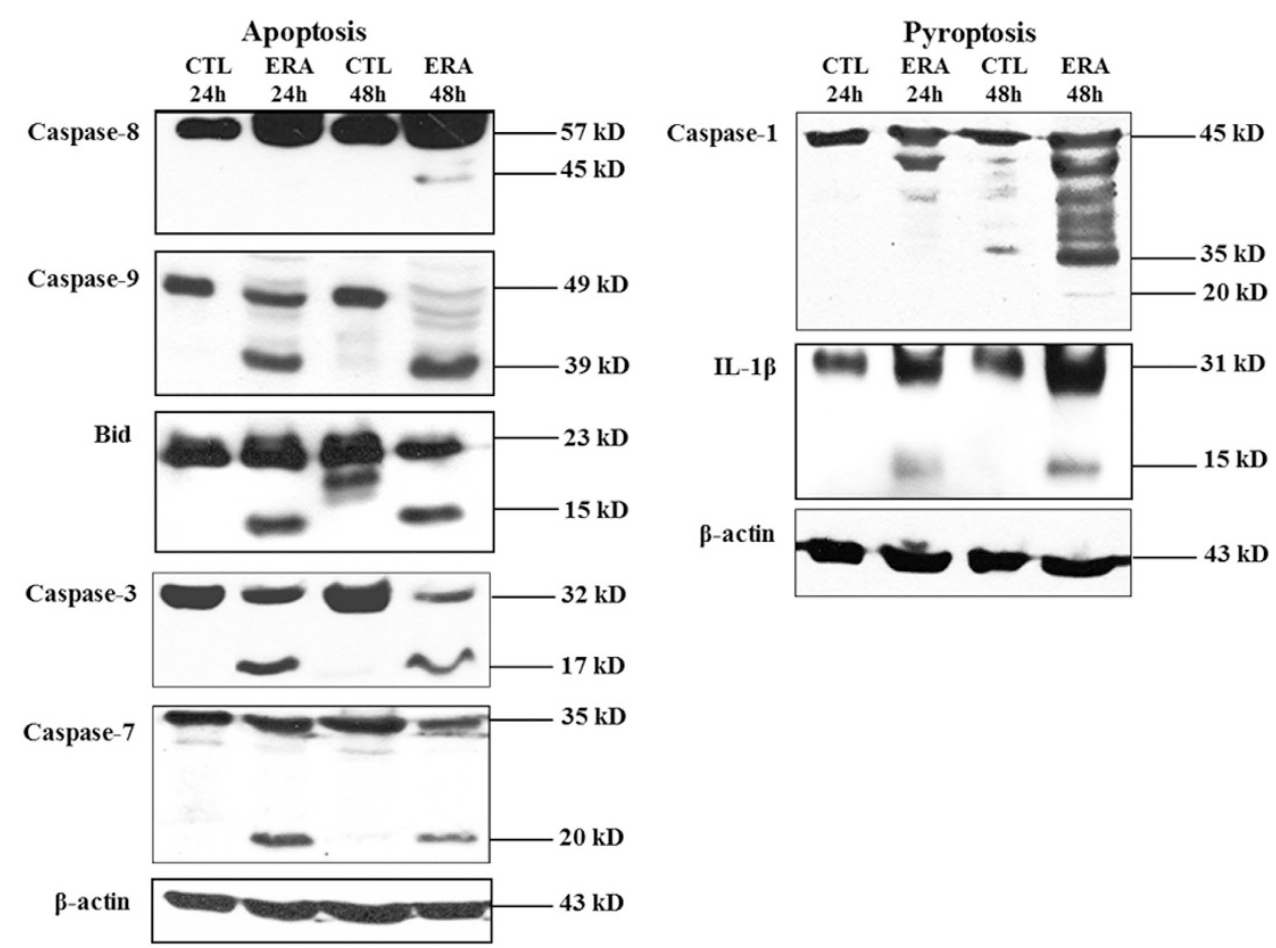

Figure 2. Activation of signaling pathways of apoptosis and pyroptosis in rabies virus-infected Mf4/4. Analysis of the proteolytic activation of caspases-1, -3, -7, -8, and -9, IL-1 $\beta$ and Bid in MF4/4 cells inoculated by ERA. Western blots were performed using antibodies specific for the active and inactive forms of these proteins. Upon activation, the protein is cleaved and appears as a smaller band representing the active protein on the blot. Total cellular lysates were prepared 24 and $48 \mathrm{~h}$ after virus inoculation. Uninfected Mf4/4 were prepared in parallel to each condition as negative controls (CTL). An anti- $\beta$-actin antibody was used to verify that equal amounts of protein were loaded. Data are representative of at least three independent experiments.

infection of Mf4/4 by ERA involves the proteolytic activation of several caspases contributing to cell death.

Caspase-3 deficiency protects against rabies virus-induced apoptosis in BMDM

BMDM from wild-type (WT) and deficient mice (caspase-1/11, -3 , or -7 deficient) were used to assess whether the main effectors of pyroptosis (caspase- 1 and -11) and apoptosis (caspase- 3 and -7) are involved in rabies virus-induced cell death. After isolation, cells were infected with either ERA or CVS-11 and cell adherence was assessed by crystal violet staining as a measure for cell viability $48 \mathrm{hpi}$. Interestingly, a significant protective effect on BMDM viability was observed in caspase- $3^{-1-}$ macrophages infected by ERA or CVS-11 virus (Figures $3 a$ and b). Indeed, an average of $90 \%$ viability was observed in caspase- $3^{-/-}$BMDM infected with CVS-11 compared to an average of $66 \%$ in WT cells. For ERA virus, an average of $71 \%$ viability was observed in caspase- $3^{-/-}$BMDM, compared to an average of $56 \%$ in WT cells. In caspase- $1 / 11^{-/-}$or caspase- $7^{-/-}$ BMDM, no significant protective effect against cell death was observed. In parallel, we also examined the effect of caspase-1/11, -3 , or -7 deficiencies on rabies virus replication in macrophages. WT and deficient BMDM were infected with ERA and CVS-11 and the viral load was determined by RT-qPCR. Results obtained with caspase- $7^{-/-}$or caspase- $3^{-/-}$in comparison to WT BMDM following $48 \mathrm{hpi}$ tended to be highly variable (Figures $3 \mathrm{c}$ and d). Nevertheless, the mean viral load KO/WT ratios obtained with ERA or CVS-11 suggest that caspases-7 may affect rabies virus replication. In contrast, the variability observed in KO/WT viral load ratios obtained with caspases-1 $1^{-/-}$macrophages after ERA or CVS infection was low, with means being just below 1.0, suggesting no or low impact for the caspase on viral replication.
Deficiency of caspase-3, but not caspase-1/11, -7 , or IL-1 $\beta /$ IL-18 delays CVS-11-induced disease in mice

The impact of cell death on rabies pathogenicity is controversial. To better understand the impact of apoptosis and pyroptosis in vivo during infection with a virulent rabies strain, we studied the impact of caspase-1/11, -3 , or -7 deficiency in mice on rabies virusinduced morbidity and mortality following intranasal inoculation with CVS-11. Since the production of active IL-1 $\beta$ and IL-18 depends on caspase- 1 activity, we also analysed the impact of IL-1 $\beta / I L-18$ double deficiency in the same experimental set-up. Neutralizing antibody concentrations in serum and viral load in the brain were determined at the moment of killing.

WT and deficient mice inoculated with CVS-11 strain developed severe disease, beginning with weight loss and appearance of a hunched back, followed by motoric incoordination, a wasp waist and in the last stage of the disease depression and paralysis of the hind legs. All mice reached the clinical end point, requiring killing, about 1-3 days after the appearance of the first disease symptoms. For caspase- $3^{-/-}$mice, the onset of symptoms was delayed by 2 days, compared to their corresponding WT mice (Figure $4 \mathrm{~b}$ ). At $8 \mathrm{DPI}$, most of the WT, caspase-1/11, -7 , and IL $1 \beta$ / IL-18-deficient mice had reached the maximal clinical score, while the caspase $-3^{-1-}$ mice were only starting to show the initial symptoms of the disease $(P<0.01)$. Overall, mortality was $100 \%$ in WT and caspase-deficient mice, but the median survival time was significantly longer for caspase- $3^{-/-}$mice $(P<0.01)$. This was not the case for caspase-1, -7 , and IL-1 $\beta / \mathrm{IL}-18$-deficient mice. The median survival time was 8 DPI in WT mice, caspase-1/11, -7 , and IL $1 \beta /$ IL-18-deficient mice and 10-11 DPI in caspase- $3^{-\prime-}$ mice (Figure $4 a$ ). We have also determined the effect of caspase-1, -3 , -7 , or IL1 $\beta /$ IL-18 deficiency on the final cerebral virus load at the moment of killing ( = peak of disease), but there was no significant difference (Figure 4c). At the moment of killing (8-11 DPI), none of 


\section{CVS-11 infection}
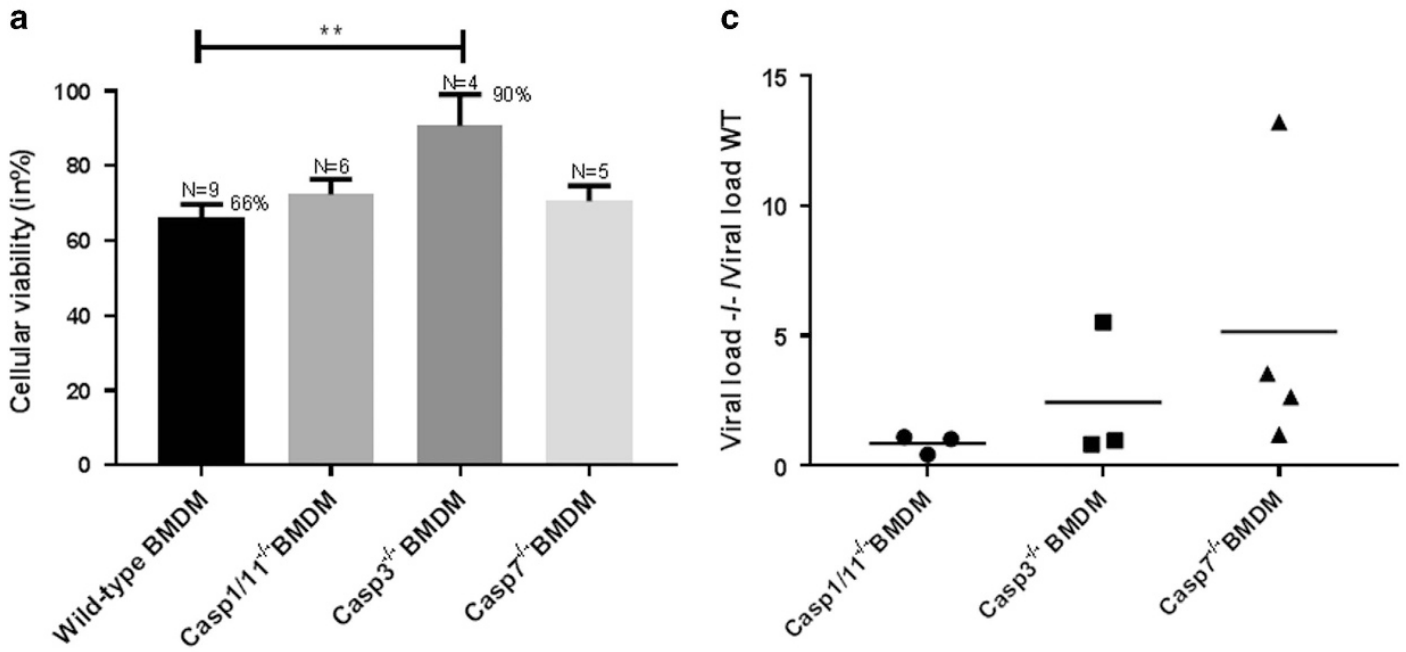

ERA infection

b

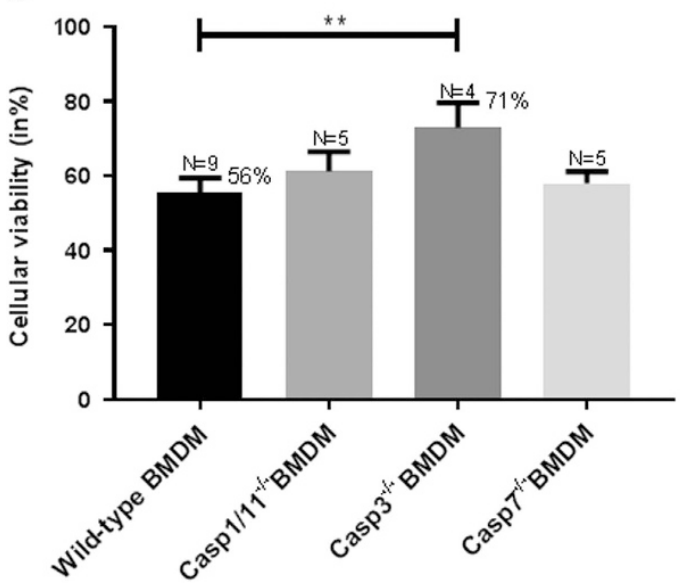

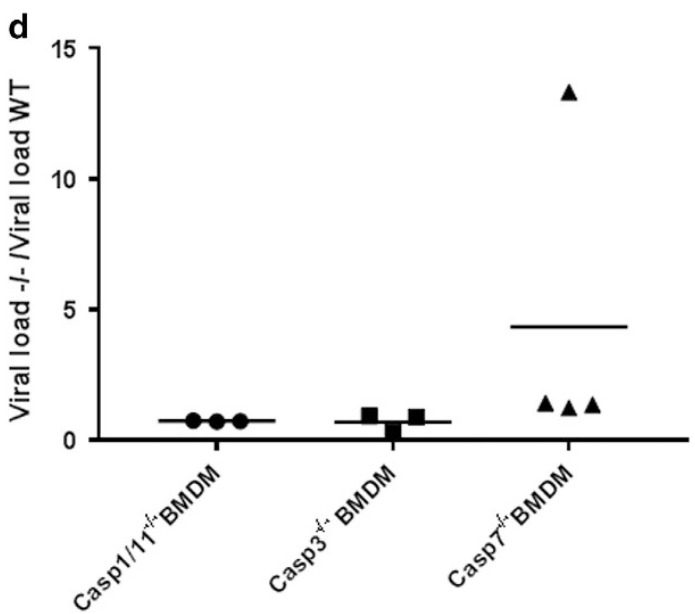

Figure 3. Cellular viability and viral load of caspases-1/11, -3, or -7-deficient primary BMDMs inoculated by CVS-11 (a, c) or ERA (b, d) virus. $(\mathbf{a}, \mathbf{b})$ Cellular viability was determined at $48 \mathrm{hpi}$ using the crystal violet staining method to measure the percentage of viable adherent cells. $P$-value was calculated using an unpaired $t$-test (each group of deficient BMDM compared to the WT group) and was indicated as follows: $P$-value $<0.01\left(^{* *}\right)$. A protector effect on the viability of the cells was observed in caspase- $3^{-/-}$macrophages inoculated with ERA or CVS-11. Data were pooled and are representative of at least four independent experiments. They are presented as mean values \pm S.E.M. (c and d) Viral load was determined 48 hpi by RT-qPCR following CVS-11 or ERA infection. Results are presented as a ratio compared to the WT cells. Each point represents one independent experiment.

the mice had developed antibody levels above the protective threshold of $0.5 \mathrm{IU} / \mathrm{ml}$ (Figure $4 \mathrm{~d}$ ). In conclusion, these results indicate that apoptosis through caspase-3 promotes early onset of disease upon infection with a virulent strain of rabies virus, but has no effect on final viral load in the brain or on final disease outcome.

Deficiency of caspase-1/11, but not caspase-3, -7 , or IL-1 $\beta /$ IL-18 increases ERA-induced morbidity in mice

ERA virus is not lethal and induces only minor symptoms in immunocompetent WT mice. The impact of cell death following infection with an attenuated rabies strain has been poorly investigated in vivo. We found that intranasal inoculation of ERA virus in WT, caspase-3, -7 , or IL $1 \beta / \mathrm{IL}-18^{-/-}$mice led to the development of minor symptoms such as weight loss or motoric incoordination from 11-18 DPI. In contrast, caspase- $1 / 11^{-/-}$mice developed more severe symptoms, such as hunched back and paralysis, which lasted for a longer period, with some symptoms still present at $35 \mathrm{DPI}$, the end of the observation period. At 20 and $21 \mathrm{DPI}$, clinical scores were significantly higher for caspase-1/11 $1^{-/-}$ compared to other mice (Figure $5 \mathrm{~b}$ ). Interestingly, such an ERAinduced morbidity was not observed with IL-1 $\beta / \mathrm{IL}-18^{-/-}$mice, suggesting that the impact of caspase- $1 / 11^{-/-}$was not due to lack of these cytokines. No mortality was observed in WT and caspase$1 / 11,-3,-7$, or IL-1 $\beta /$ IL-18-deficient mice inoculated with ERA.

We next determined if caspase or IL-1 $\beta /$ IL-18 deficiency had an impact on viral load in the brain and neutralizing antibody production. ERA virus-inoculated mice were killed at $35 \mathrm{DPI}$. At that stage, viral RNA was still detectable in the brain, with no significant differences between deficient and WT mice (Figure 5c). This persistence of ERA virus RNA was not linked to disease, as most symptoms had disappeared before $35 \mathrm{DPI}$. All mice developed a strong antibody response, largely above $0.50 \mathrm{IU} / \mathrm{ml}$, and there was no significant difference in antibody titers 
CVS-11 infection in vivo

a

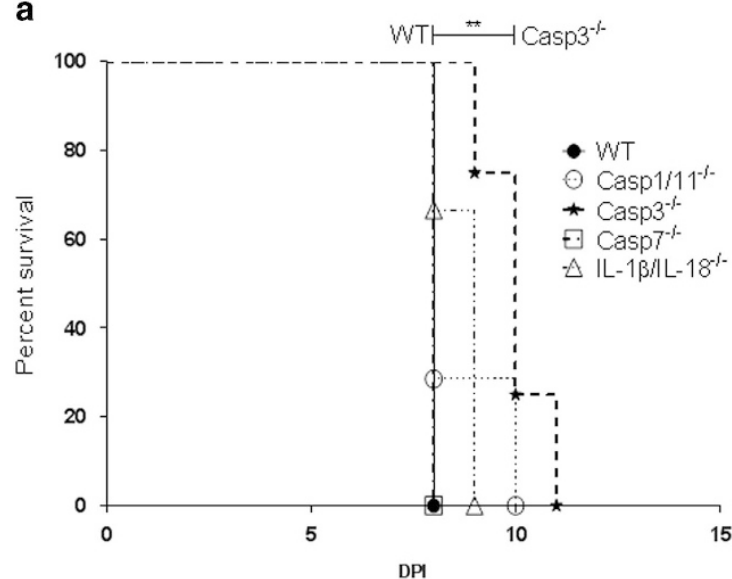

C

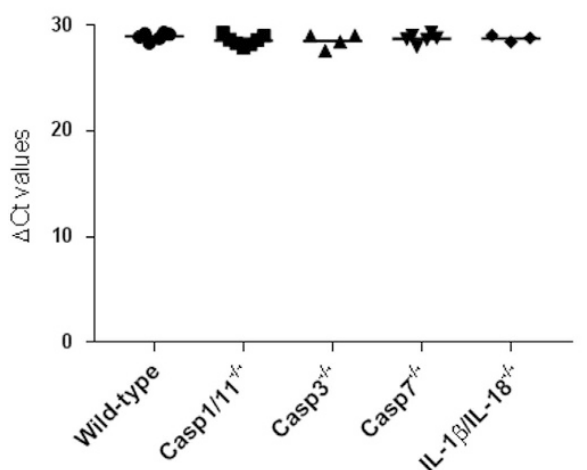

b

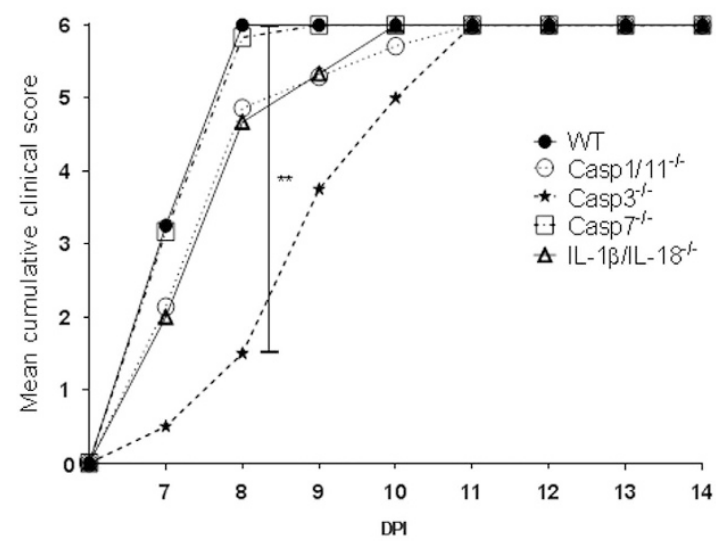

d

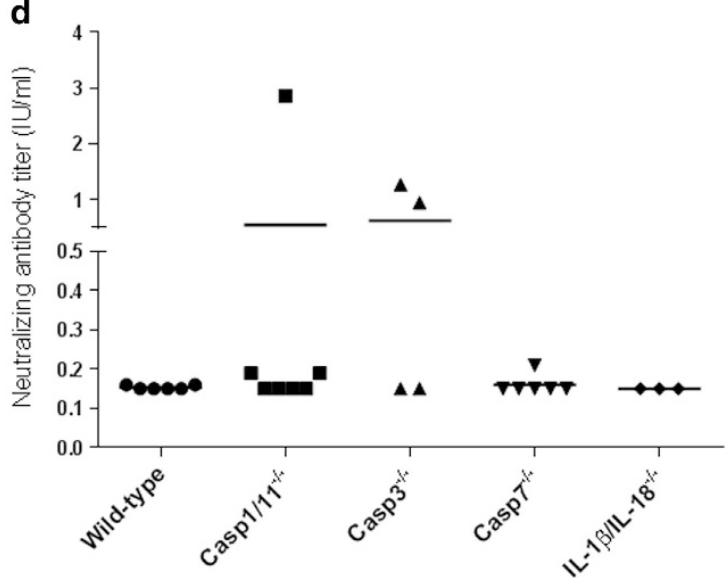

Figure 4. Impact of a deficiency in caspase-1/11, -3 , or -7 or IL-1 $\beta / \mathrm{IL}-18$ in mice on rabies disease progression, mortality, brain viral load, and neutralizing antibody response upon infection with a virulent strain of rabies. WT $(n=6)$, caspase- $1 / 11^{-1-}$ mice $(n=7)$, caspase- $3^{-1-}$ mice $(n=4)$, caspase- $7^{-1-}$ mice $(n=6)$, and IL-1 $\beta / I L-18^{-/-}$mice $(n=3)$ were inoculated intranasally with the virulent CVS-11 virus $\left(10^{2.5}\right.$ TCID $50 /$ mouse). Disease progression and mortality within each group was evaluated by mean clinical score per mouse (b) and survival curves (a), respectively. P-value was calculated using a log-rank test (survival curves) and an ANOVA test followed by Bonferroni multiple comparison post-test (mean score per mouse) and was indicated as follows: $P$-value $<0.05\left(^{*}\right) ; P$-value $<0.01\left(^{* *}\right)$. (a) Survival curves of WT mice and caspase-3-deficient mice were significantly different $(* *)$. (b) The mean clinical score per mouse was significantly different between WT and caspase- $3^{-1-}$ mice at 8 DPI. Caspase-3 deficiency delayed CVS-11-related disease, but had no effect on final lethal outcome. (c) Brain tissue was sampled upon peak clinical score and viral load measured by RT-qPCR. P-value was calculated with an ANOVA test followed by Bonferroni multiple comparison post-test. No significant difference could be observed between WT mice and deficient mice. (d) The neutralizing antibody titer was evaluated by rapid fluorescent focus inhibition test and expressed in IU/ml. P-value was calculated by an ANOVA test followed by Bonferroni multiple comparison post-test. Most mice were unable to mount an antibody response ( $>0.5 \mathrm{IU} / \mathrm{ml})$ prior to killing. No significant difference was observed between WT and deficient mice. Two out of four caspase- $3^{-/-}$mice had developed antibody titers $>0.5 \mathrm{IU} / \mathrm{ml}$, which might be because they survived long enough to allow an antibody response.

between WT and deficient mice (Figure $5 \mathrm{~d}$ ). In conclusion, our results suggest that caspase- 1 or caspase- 11 controls attenuated ERA strain infection and disease within the central nervous system.

\section{DISCUSSION}

Apoptosis and pyroptosis can be induced by a wide variety of stimuli, including viral infection. In this work, we analysed the impact of key mediators of apoptosis (caspase-3 and -7) and pyroptosis (caspase-1 and -11) on rabies virus production, cell death, morbidity, and mortality. Cells of the immune system seem prone to undergo cell death upon infection with rabies virus. ${ }^{20}$ This seems particularly the case for the ERA-attenuated strain, which appears also better fit than CVS-11 to replicate in these cells. For the in vitro studies, macrophages were used as the infection model, since these cells are very susceptible to infection, ${ }^{31-33}$ especially with the ERA strain, and undergo distinguishable cell death upon infection. Infection of macrophages and their resulting cell death was rabies strain-dependent: we observed significantly higher infection rates, accompanied by a strong apoptotic response, with the ERA strain than with the CVS-11 strain. Interestingly, Thoulouze et al. ${ }^{20}$ reported that in vitro infection of a human lymphoblastoid Jurkat T-cell line with ERA, but not with CVS-11, causes apoptosis. They suggested that the improved capacity of the ERA strain to stimulate the immune system could be paradoxically linked to its ability to induce apoptosis in immune system cells. Apoptosis of infected cells may augment the presentation of viral antigen and then efficiently activate the immune system. 
ERA infection in vivo

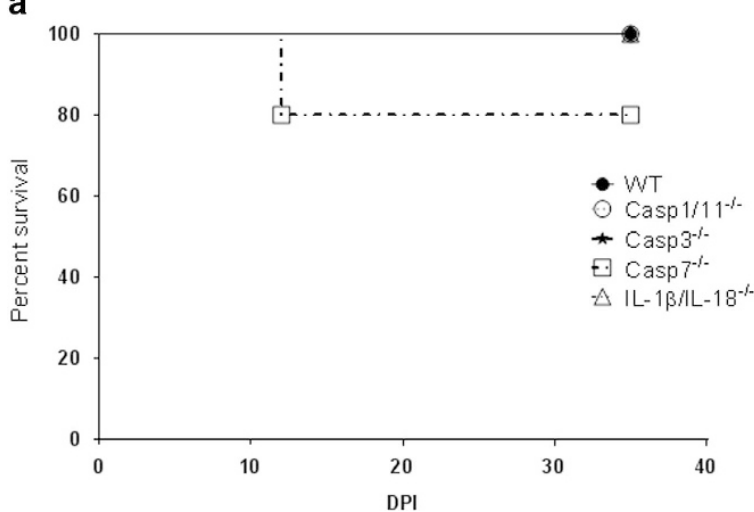

C

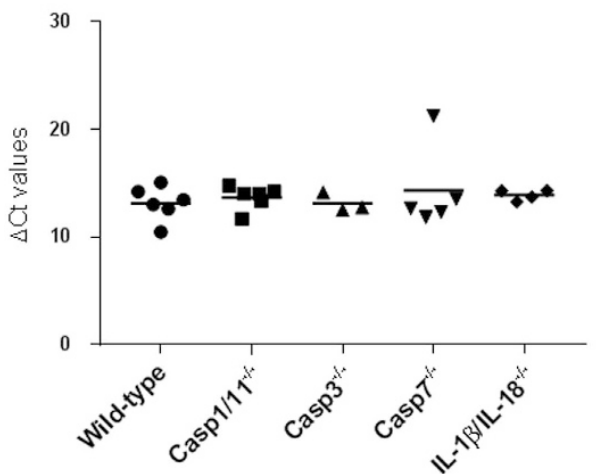

b

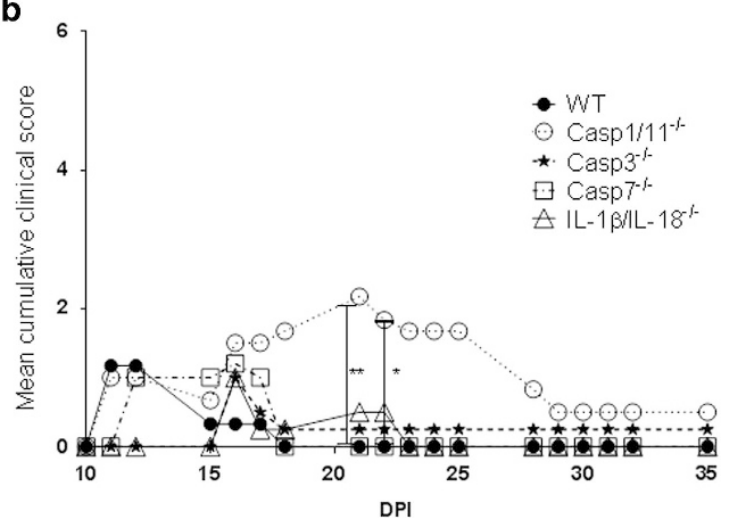

d

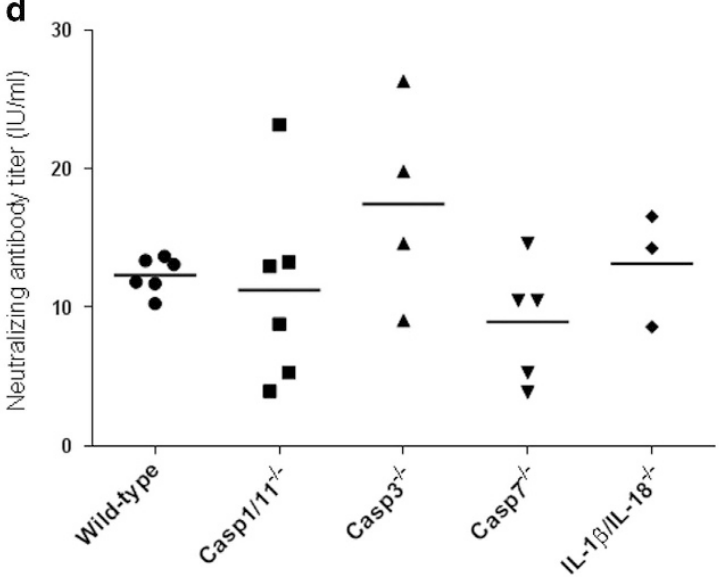

Figure 5. Impact of a deficiency in caspase-1/11, -3 , or -7 or IL-1 $\beta / \mathrm{IL}-18$ in mice on rabies disease progression, mortality, brain viral load, and neutralizing antibody response upon infection with an attenuated strain of rabies. WT $(n=6)$, caspase- $1 / 11^{-1-}$ mice $(n=6)$, caspase- $3^{-1-}$ mice $(n=4)$, caspase- $7^{-1-}$ mice $(n=5)$, and IL-1 $\beta / \mathrm{IL}-18^{-/-}$mice $(n=4)$ were inoculated intranasally with the attenuated ERA virus $\left(10^{5}\right.$ TCID $50 /$ mouse). Disease progression and mortality within each group was evaluated by mean clinical score per mouse (b) and survival curves (a), respectively. $P$-value was calculated using a log-rank test (survival curves) and an ANOVA test followed by Bonferroni multiple comparison post-test (mean score per mouse) and was indicated as follows: $P$-value $<0.05\left({ }^{*}\right) ; P$-value $<0.01(* *)$. (a) All mice survived the infection except for one caspase- $7^{-1-}$ mouse. (b) The mean clinical score per mouse was significantly different between WT and caspase-1 ${ }^{-1-}$ inoculated with ERA virus at 21 and 20 DPI (c). Brain tissue was sampled at 35 DPI (except for one mouse) and viral load measured by RT-qPCR. $P$-value was calculated with an ANOVA test followed by Bonferroni multiple comparison post-test. No significant difference could be observed between WT mice and deficient mice. (d) The neutralizing antibody titer was evaluated by rapid fluorescent focus inhibition test and expressed in IU/ml. P-value was calculated by an ANOVA test followed by Bonferroni multiple comparison post-test. No significant difference was observed between WT and deficient mice, but antibody titers seemed higher in caspase- $3^{-/-}$mice.

Another study, conducted on the brain of deceased rabies patients, demonstrated immunostained cleaved caspase-3 in microglial cells, which are from the macrophage lineage. ${ }^{18}$ In our study, we demonstrate that caspases-1/11, $-3,-7,-8$, and -9 , IL-1 $\beta$ and the Bid factor are activated in Mf4/4 cells upon infection with ERA. They are also activated after infection with CVS-11, but to a lesser extent which is probably linked to the lower rate of infection of Mf4/4 cells. By western blot analysis, we found that caspase- 9 and Bid factor were activated earlier than caspase-8, suggesting that the apoptotic process is initiated by the activation of the apoptosome via the mitochondrial pathway and Bid factor proteolysis. ${ }^{34}$ The IL-1 $\beta$ activation demonstrates the involvement of caspase- 1 in the inflammatory process induced by the ERA strain in Mf4/4.

Our results on primary BMDM suggest a predominant role of caspase- 3 in cell death induced by ERA and CVS-11 strains in macrophages, while caspase-1/11 or -7 does not seem to be necessary. In vivo, apoptotic (cytochrome c, caspase-3) and pyroptotic (caspase-1, IL-1 $\beta$ ) genes were shown to be upregulated following rabies virus infection. ${ }^{35}$ In our study, the onset of disease upon rabies virus infection was significantly delayed in caspase$3^{-/-}$mice, compared to WT, IL-1 $\beta /$ IL-18, caspase- $1 / 11$, and caspase-7-deficient mice. This might be explained by an involvement of neuronal apoptosis in the cerebral dysfunction associated with rabies disease. Indeed, it was shown that CVS-11 produces neuronal apoptosis in the brain of mice after intracerebral inoculation, without implication of the adaptive immune system, as demonstrated in nude and Rag1 mice; ${ }^{36,37}$ moreover, we observed immunostaining for cleaved caspase- 3 in neuronal cells of CVS-11-infected mice in our laboratory. In another study, infection of bax-deficient mice with CVS-11 reduced apoptosis of neurons from the dentate gyrus and cortical neurons, but still yielded $100 \%$ mortality. ${ }^{38}$ Moreover, the apoptotic cell death of neurons is a mechanism known to be implicated in other types of infectious brain disease, such as reovirus-induced encephalitis. ${ }^{39}$ Other studies showed no apoptosis in neurons of rabies virusinfected mice infected intramuscularly by CVS-11, but apoptosis was detected in microglial cells and T lymphocytes, whereas 
neurons died rather by necrosis. ${ }^{40}$ In another study, apoptosis was not detected in the brain of experimentally infected mice infected with a street rabies virus (silver-haired bat rabies virus), although rabies virus antigens were distributed widely within the CNS. ${ }^{41}$ The variable results in literature could be related to differences in virus strain, route of inoculation, or the strain of laboratory animals used. ${ }^{15,23}$ Viral loads were similar in all deficient and WT mice, including caspase $-3^{-1-}$ mice, despite the delay in disease observed. However, it is important to mention that samples were only taken at the time of killing, when all mice had developed a similar level of disease. Analysis of the viral load at comparable and earlier time points should be performed for more firm conclusions.

There is good evidence that pyroptosis can benefit the host during infection but if too many host cells undergo pyroptosis, detrimental effects may occur due to the release of inflammatory cytosolic mediators or the depletion of host cells, which highlights the notion of good versus bad inflammation. Previous studies have shown that increased IL-1 $\beta$ mRNA levels were found in brains of paralytic rabid dogs during early stages of infection ${ }^{42}$ and IL-1 $\beta$ release and Nlrp3 inflammasome activation were demonstrated in murine dendritic cells infected by rabies virus. ${ }^{30}$ Still, the impact of pyroptosis in rabies pathogenicity is not well established. We were not able to prove the involvement of caspase- 1 or -11 or IL-1 $\beta$ / IL-18 on CVS-11-induced morbidity or mortality. On the other hand, infection of caspase-1/11 $1^{-/}$mice with the ERA strain showed a worsening of symptoms in comparison to WT mice. Inflammation is thought to promote the viral clearance in rabies virus infection, especially when the strain is attenuated. ${ }^{43,44}$ So, the capacity of caspase- 1 to take part in the inflammatory process by cleaving IL-1 $\beta$ could have been a reasonable explanation. However, in contrast with caspase- $1 / 11^{-/-}$mice, inoculation of $\mathrm{IL}-1 \beta / \mathrm{IL}-18^{-/-}$mice with the ERA strain induced no worsening of symptoms in comparison with WT mice. The higher morbidity observed in caspase- $1 / 11^{-/-}$mice is thus probably not linked to IL-1 $\beta /$ IL-18 activation and secretion. It is important to note that the caspase- $1 / 11^{-/-}$mice were initially considered as caspase- $1^{-1-}$, but the double deficiency with caspase-11 was later recognized. ${ }^{28}$ Thus, the results observed in our study might also involve caspase11 , which is also implicated in the pyroptosis pathway.

In conclusion, in this study, infection of macrophages was shown to lead to apoptotic and pyroptotic cell death. In vivo, apoptosis mediated through caspase- 3 seems more detrimental than protective for the host upon infection with a virulent strain (CVS-11). Blocking apoptosis with caspase-3 inhibitors might therefore have beneficial effect on disease. In contrast, during attenuated rabies strain infection, pyroptosis mediated by caspase-1 and/or caspase-11 plays a role in limiting the disease caused by an attenuated rabies virus strain (ERA).

\section{MATERIALS AND METHODS}

Virus

The highly virulent neurotropic CVS-11 strain and the attenuated ERA virus, used as an oral vaccine for immunization of wild life, were obtained from the American Type Culture Collection (references: VR959 and VR322, respectively). ${ }^{45}$ Virus stocks were grown in baby hamster kidney (BHK)21 cells. The lysates of infected cell cultures were centrifuged at $20000 \times g$ for $20 \mathrm{~min}$ at $4{ }^{\circ} \mathrm{C}$ and the infectious dose was titrated in BHK-21 cells (see below).

\section{Antibodies and reagents}

Crystal violet was purchased from UCB (Brussels, Belgium). FITC-coupled anti-nucleocapsid rabbit antibody was from Bio-Rad Laboratories (Hercules, CA, USA). Horseradish peroxydase (HRP)-linked anti-rat IgG, mousespecific anti-caspase-8, -9 , cleaved caspase- 7 and -3 polyclonal antibodies were from BIOKE (Leiden, The Netherlands). Polyclonal anti-mouse IL-1 $\beta$ / IL-1F2 antibody, monoclonal anti-mouse BID, and monoclonal anti-mouse
IL- $1 \beta$ were from R\&D systems (Minneapolis, MN, USA). Mouse-specific anticaspase-1 antibody was made in-house as described before. ${ }^{46}$ The anti-rabies virus glycoprotein mouse monoclonal antibody and HRPlinked anti-goat IgG were from Santa Cruz (Santa Cruz, CA, USA). HRP-linked anti-mouse and anti-rabbit antibody were from GE Healthcare (Waukesha, WI, USA). HRP-conjugated anti- $\beta$-actin antibody was from ICN Biomedicals (Irvine, CA, USA).

\section{Cell culture and cellular infection}

Mf4/4 is an immortalized cell line of spleen macrophages derived from $\mathrm{C} 57 \mathrm{BL} / 6$ mice. ${ }^{47} \mathrm{BHK}-21$ are hamster kidney cells that are routinely used to propagate laboratory strains of rabies virus. Mf4/4 were grown at $37^{\circ} \mathrm{C}$ and $5 \% \mathrm{CO}_{2}$ in RPMI-1640 (Lonza, Verviers, Belgium) supplemented with $10 \%$ fetal bovine serum, $1 \mathrm{mM}$ sodium pyruvate, $100 \mathrm{U} / \mathrm{ml}$ of penicillin, and $100 \mu \mathrm{g} / \mathrm{ml}$ of streptomycin. BHK-21 were grown in DMEM (Gibco, Paisley, UK) supplemented with $10 \%$ fetal bovine serum, $100 \mathrm{U} / \mathrm{ml}$ of penicillin, $100 \mu \mathrm{g} / \mathrm{ml}$ of streptomycin, and $0.25 \mu \mathrm{g} / \mathrm{ml}$ of amphotericin $\mathrm{B}$.

BMDMs were isolated from femurs and tibias of $6-12$ weeks old C57BL/6 mice. Bone marrow was flushed from the bones with RPMI-1640 and following centrifugation, cells were suspended in RPMI-1640 supplemented with $20 \mathrm{ng} / \mathrm{ml}$ macrophage-colony stimulating factor (Peprotech, Rocky Hill, CT, USA) and seeded in a T75 flask. Non-adherent cells were washed away 4 days later. After 6 days, adherent differentiated macrophages were collected and reseeded in plates. Macrophage purity was $\sim 98.8 \%$ as assessed by flow cytometry using the phycoerythrinconjugated monoclonal antibody BM8 anti-F4/80 macrophage marker (eBioscience, Hartfield, UK).

For cellular infection, Mf4/4 were seeded and infected $24 \mathrm{~h}$ later, with the CVS-11 or ERA strains at a multiplicity of infection of 1. BMDMs were seeded and infected $2 \mathrm{~h}$ later with rabies virus at multiplicity of infection 1 in the presence of macrophage-colony stimulating factor. The cells were washed $3 \mathrm{~h}$ later two times with medium. At the indicated time following infection, cells were washed and fixed with methanol for $5 \mathrm{~min}$ to measure cell adherence as an indicator for cell viability. Alternatively, cells were frozen and used for viral titration or collected for RT-qPCR analysis.

\section{Measurement of cell survival}

Adherence of Mf4/4 or BMDM was used as a measure for cell survival and was monitored $48 \mathrm{hpi}$ by crystal violet staining. Adherent cells fixed with methanol were stained with $0.1 \%$ crystal violet for $10 \mathrm{~min}$ and washed twice with PBS. Crystal violet-stained cells were solubilized with a $1 \%$ sodium dodecyl sulfate (SDS) and absorbance at $595 \mathrm{~nm}$ was measured with a spectrophotometer (Model 680 microplate reader, BioRad, Hercules, CA, USA). Cell survival percentage was calculated using the following equation: $100 \% \times($ A595/655 treated cells—A595/655 medium)/(A595/655 untreated cells-A595/655 medium). Experiments were carried out in triplicate.

\section{Virus titration}

Cells and medium underwent three consecutive freeze-thaw cycles at $-80^{\circ} \mathrm{C}$. Supernatant and cells were collected and infectious rabies virus particles were titrated in BHK-21. Results were expressed in $50 \%$ tissue culture infective dose $\left(\mathrm{TCID}_{50}\right) / \mathrm{ml}$. Virus titration was performed according to the Manual of Diagnostic Tests and Vaccines for Terrestrial Animals (Office International des Epizooties, 2008).

\section{Anti-nucleocapsid rabies virus staining}

Mf4/4 cells were infected with ERA virus or CVS-11 as described above. At $48 \mathrm{hpi}$, cells were fixed with $75 \%$ acetone for $30 \mathrm{~min}$ at room temperature and incubated with FITC-coupled anti-rabies virus nucleocapsid rabbit antibody for $30 \mathrm{~min}$ at $37^{\circ} \mathrm{C}$. Next, a DNA Hoechst staining was performed for $5 \mathrm{~min}$ at $37^{\circ} \mathrm{C}$. Cells were washed with distilled water and the percentage of rabies virus-infected cells was determined using fluorescence microscopy (Nikon eclipse TS100).

\section{Cellular caspase activation assay}

Mf4/4 cells were infected with CVS-11 or ERA virus in 24-well plates. At $48 \mathrm{hpi}$, cells were incubated with the green fluorescent caspases inhibitor (FLICA) according to the manufacturer's instructions (apoptosis detection kit caspases assay, Eurobio-Abcys, Les Ulis, France). After washing steps, 
the percentage of activated caspase-positive cells was determined using fluorescence microscopy (Nikon eclipse TS100).

\section{Western blotting and immunoprecipitation}

Mf4/4 cells were infected with ERA virus at a multiplicity of infection of 1 , as described above. Mf4/4 cells inoculated with medium were used as a control. Cells and media were collected at 24 and $48 \mathrm{~h}$ post virus inoculation. Cells were centrifuged at $2500 \times \mathrm{g}$, supernatant was collected for immunoprecipitation or discarded as indicated. The pellet was resuspended and boiled for $10 \mathrm{~min}$ in sample buffer containing: 6\% SDS, 1.4 M $\beta$-mercaptoethanol, 20\% glycerol, $0.01 \%(\mathrm{w} / \mathrm{v})$ bromophenol blue, and $125 \mathrm{mM}$ Tris- $\mathrm{HCl}, \mathrm{pH} 6.8$.

For IL-1 $\beta$ immunoprecipitation, collected supernatant media was supplemented with $10 \%$ lysis buffer $(50 \mathrm{mM}$ Hepes pH 7.6, $200 \mathrm{mM} \mathrm{NaCl}$, $0.1 \%$ de NP40, and $5 \mathrm{mM}$ EDTA), a protease inhibitors tablet (Roche, Basel, Switzerland) and $2 \mu \mathrm{g}$ of monoclonal anti-mouse IL-1 $\beta$. Following $24 \mathrm{~h}$ incubation on a turning wheel at $4^{\circ} \mathrm{C}$, media were incubated with $20 \mu \mathrm{l}$ resuspended protein $\mathrm{G}$-sepharose beads (Amersham Bioscience, Freiburg, Germany) at room temperature under gentle agitation. Following $3 \mathrm{~h}$ of incubation, sepharose beads were washed four times in lysis buffer and then resuspended and boiled for $5 \mathrm{~min}$ in sample buffer. Protein extracts and immunoprecipitation products were fractionated by SDS-PAGE and transferred to nitrocellulose membranes. Blocking, antibody incubation steps, and washing of the membrane were performed in PBS supplemented with $3 \%$ skimmed milk and $0.05 \%$ Tween 20 . Blots were incubated with the indicated primary antibody overnight. Membranes were consequently incubated for $1 \mathrm{~h}$ with HRP-conjugated secondary antibodies to mouse, rabbit, rat, or goat immunoglobulin according to needs. Immunoreactive proteins were visualized using the chemiluminescence kit 'Immobilon Western Chemiluminescent HRP Substrate' (Millipore, Billerica, MA, USA) and signals were captured by exposure to film (GE Healthcare, Little Chalfont, UK).

\section{RT-qPCR analysis}

RNA extraction was performed using RNeasy Mini kit (Qiagen, Hilden, Germany) according to the manufacturer's instructions. Reverse transcription and q-PCR were performed as described in Rosseels et al. ${ }^{48}$ Two primers (forward and reverse, sequences are accessible on demand; Eurogentec, Seraing, Belgium) located in the nucleoprotein $\mathrm{N}$ genome region were used for the detection of ERA and CVS-11 strains. The cellular housekeeping gene, GAPDH, was used for normalization. All samples were analyzed in duplicates. Amplification was performed on an iCycler iQ from BioRad in a 96-well optical plate format, using the following program: 2 min at $95{ }^{\circ} \mathrm{C}$ followed by 45 cycles of $20 \mathrm{~s}$ at $95^{\circ} \mathrm{C}$ and $30 \mathrm{~s}$ at $62^{\circ} \mathrm{C}$. A melting curve analysis was performed in order to verify the specificity of amplicons. Quantification of gene expression was performed using the comparative delta $\mathrm{Ct}$ method: delta cycle thresholds $(\Delta \mathrm{Ct})$ values were calculated using the following formula: $\Delta \mathrm{Ct}=\mathrm{Ct}_{\text {ref }}-\mathrm{Ct}_{\text {sample, }}$ with $\mathrm{Ct}_{\text {ref }}$ equal to 45 , which is the number of cycles of this QPCR program.

\section{Mice}

All mice were bred under specific pathogen-free conditions, and in all experiments sex- and age-matched animals were used. Conditional caspase $-7^{\mathrm{f} / \mathrm{fl}}$ were generated on a mixed 129S6/Swiss background and back-crossed for 10 generations to the C57BL/6J background before crossing with Sox $2 \mathrm{Cre}$ mice to generate caspase- $7^{-/-}$mice. ${ }^{49}$ Caspase$1 / 11^{-1-}$, caspase- $3^{-/-}$, and IL1 $\beta /$ IL $18^{-1-}$ mice on a C57BL/6J background were kindly provided by Dr. R Flavell (Howard Hughes Medical Institute, Chevy Chase, MD, USA), Dr. T Mak (The Campbell Family Cancer Research Institute, Toronto, Canada), and A Zychlinsky (Max Planck Institute, Berlin,

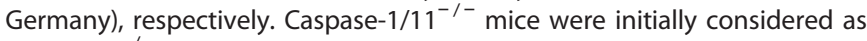
caspase $-1^{-1-}$, but the double deficiency with caspase-11 was later recognized. ${ }^{28}$ Mice were housed in temperature-controlled, airconditioned facilities with 14/10-h light/dark cycles and food and water ad libitum, and used at the age of 8-12 weeks. All experimental procedures were approved by the Ethical Committee of the IPH and the Veterinary and Agrochemical Research Centre (VAR) (advice nr. 060217-03). Mice were inoculated by intranasal inoculation as described in Rosseels et al., ${ }^{48}$ with $10^{2.5} \mathrm{TCID}_{50}$ of CVS-11 virus or $10^{5} \mathrm{TCID}_{50}$ of ERA virus.
Clinical follow-up and sampling

Mice were observed daily for signs of disease throughout the experiment until 35 days post inoculation (DPI). Disease signs were scored as follows: no signs $=0,>20 \%$ weight loss $=1$, depression $=1$, hunched back $=1$, wasp waist $=1$, incoordination $=1$, and paralysis of hind legs $=1$. Mice that reached a score of 6 were killed by cervical dislocation. A cumulative daily clinical score per mouse was obtained by adding the scores for each parameter. Disease progression was represented by a curve of the relative cumulative score (scores of all mice of a group/number of mice of this group). Killed mice are included in the curve by adding the score 6 for each killed mouse. Mice with no apparent rabies disease signs were killed 35 DPI. Blood and brain tissue from each mouse were sampled at the time of killing for antibody measurement by Rapid Fluorescent Focus Inhibition Test and viral load determination by RT-qPCR analysis, respectively.

\section{Titration of neutralizing antibody by rapid fluorescent focus} inhibition test

Neutralizing antibodies were titrated with the rapid fluorescent focus inhibition test according to the Manual of Diagnostic Tests and Vaccines for Terrestrial Animals (Office International des Epizooties, 2008). Neutralizing antibody titers are expressed as international units $(\mathrm{IU}) / \mathrm{ml}$ in reference to 'The Second International standard for Anti-rabies Immunoglobulin', purchased from the United Kingdom National Institute for Biological Standards and Control. A serum titer of $0.5 \mathrm{IU} / \mathrm{ml}$ is considered protective.

\section{Statistical analysis}

Statistical analysis was performed using a student $t$-test or one-way ANOVA followed by Bonferroni's multiple comparison post-test in GraphPad Prism 6. Log-rank test was used to analyse Kaplan-Meier survival curves in GraphPad Prism 6.

\section{ACKNOWLEDGEMENTS}

ML Blondiau and S Lamoral are gratefully acknowledged for their excellent technical support with the cell work. This work was supported by the Research Foundation Flanders (FWO-Vlaanderen) (1.5.121.07 and G.0657.08). FN received a fellowship from "Le Fond pour la formation à la Recherche dans I'Industrie et dans l'Agriculture » (FRIA-Wallonie) and from the Foundation David and Alice van Buuren. EK received a fellowship from the Belgian Science Policy Office (BELSPO) under the program 'Interuniversity Attraction Poles' (IAP) Phase VII (DISCOBEL IAP-7/32 project). The National Reference Centre of Rabies is partially supported by the Belgian Ministry of Social Affairs through a fund from the Health Insurance System.

\section{COMPETING INTEREST}

The authors declare no conflict of interest.

\section{REFERENCES}

1 Jackson AC. Rabies. Handb Clin Neurol 2014; 123: 601-618.

2 Hampson K, Coudeville L, Lembo T, Sambo M, Kieffer A, Attlan M et al. Estimating the global burden of endemic canine rabies. PLoS Negl Trop Dis 2015; 9: e0003709.

3 Naze F, Suin V, Lamoral S, Francart A, Brochier B, Roels S et al. Infectivity of rabies virus-exposed macrophages. Microbes Infect 2013; 15: 115-125.

4 Park $\mathrm{CH}$, Kondo $\mathrm{M}$, Inoue $\mathrm{S}$, Noguchi $\mathrm{A}$, Oyamada $\mathrm{T}$, Yoshikawa $\mathrm{H}$ et al. The histopathogenesis of paralytic rabies in six-week-old C57BL/6J mice following inoculation of the CVS-11 strain into the right triceps surae muscle. J Vet Med SCi 2006; 68: 589-595.

5 Baloul L, Lafon M. Apoptosis and rabies virus neuroinvasion. Biochimie 2003; 85: 777-788.

6 Lawson KF, Hertler R, Charlton KM, Campbell JB, Rhodes AJ. Safety and immunogenicity of ERA strain of rabies virus propagated in a BHK-21 cell line. Can J Vet Res 1989; 53: 438-444.

7 Lawson KF, Crawley JF. The ERA strain of rabies vaccine. Can J Comp Med 1972; 36: 339-344.

8 Jackson AC. Therapy of human rabies. Adv Virus Res 2011; 79: 365-375.

9 Best SM. Viral subversion of apoptotic enzymes: escape from death row. Annu Rev Microbiol 2008; 62: 171-192.

10 Lamkanfi M, Dixit VM. Manipulation of host cell death pathways during microbial infections. Cell Host Microbe 2010; 8: 44-54. 
11 Ubol S, Sukwattanapan C, Utaisincharoen P. Rabies virus replication induces Baxrelated, caspase dependent apoptosis in mouse neuroblastoma cells. Virus Res 1998; 56: 207-215.

12 Sarmento L, Tseggai T, Dhingra V, Fu ZF. Rabies virus-induced apoptosis involves caspase-dependent and caspase-independent pathways. Virus Res 2006; 121: 144-151.

13 Kassis R, Larrous F, Estaquier J, Bourhy H. Lyssavirus matrix protein induces apoptosis by a TRAIL-dependent mechanism involving caspase-8 activation. J Virol 2004; 78: 6543-6555.

14 Kojima D, Park CH, Tsujikawa S, Kohara K, Hatai H, Oyamada T et al. Lesions of the central nervous system induced by intracerebral inoculation of BALB/c mice with rabies virus (CVS-11). J Vet Med Sci 2010; 72: 1011-1016.

15 Suja MS, Mahadevan A, Madhusudana SN, Shankar SK. Role of apoptosis in rabies viral encephalitis: a comparative study in mice, canine, and human brain with a review of literature. Patholog Res Int 2011; 2011: 374286.

16 Jackson AC, Park H. Apoptotic cell death in experimental rabies in suckling mice. Acta Neuropathol 1998; 95: 159-164.

17 Jackson AC, Rasalingam P, Weli SC. Comparative pathogenesis of recombinant rabies vaccine strain SAD-L16 and SAD-D29 with replacement of Arg333 in the glycoprotein after peripheral inoculation of neonatal mice: less neurovirulent strain is a stronger inducer of neuronal apoptosis. Acta Neuropathol 2006; 111: 372-378.

18 Jackson AC, Randle E, Lawrance G, Rossiter JP. Neuronal apoptosis does not play an important role in human rabies encephalitis. J Neurovirol 2008; 14: 368-375.

19 Juntrakul S, Ruangvejvorachai P, Shuangshoti S, Wacharapluesadee S, Hemachudha T. Mechanisms of escape phenomenon of spinal cord and brainstem in human rabies. BMC Infect Dis 2005; 5: 104.

20 Thoulouze MI, Lafage M, Montano-Hirose JA, Lafon M. Rabies virus infects mouse and human lymphocytes and induces apoptosis. J Virol 1997; 71: 7372-7380.

21 Thoulouze MI, Lafage M, Yuste VJ, Kroemer G, Susin SA, Israel N et al. Apoptosis inversely correlates with rabies virus neurotropism. Ann NY Acad Sci 2003; 1010: 598-603.

22 Lafon M. Evasive strategies in rabies virus infection. Adv Virus Res 2011; 79: 33-53.

23 Yin JF, Ding YL, Huang Y, Tao XY, Li H, Yu PC et al. Comparative analysis of the pathogenic mechanisms of street rabies virus strains with different virulence levels. Biomed Environ Sci 2014; 27: 749-762.

24 Man SM, Kanneganti TD. Converging roles of caspases in inflammasome activation, cell death and innate immunity. Nat Rev Immunol 2016; 16: 7-21.

25 Lamkanfi M, Dixit VM. Modulation of inflammasome pathways by bacterial and viral pathogens. J Immunol 2011; 187: 597-602.

26 Lamkanfi M, Dixit VM. Mechanisms and functions of inflammasomes. Cell 2014; 157: 1013-1022.

27 Kayagaki N, Wong MT, Stowe IB, Ramani SR, Gonzalez LC, Akashi-Takamura S et al. Noncanonical inflammasome activation by intracellular LPS independent of TLR4. Science 2013; 341: 1246-1249.

28 Kayagaki N, Warming S, Lamkanfi M, Vande WL, Louie S, Dong J et al. Non-canonical inflammasome activation targets caspase-11. Nature 2011; 479: 117-121.

29 Gram AM, Frenkel J, Ressing ME. Inflammasomes and viruses: cellular defence versus viral offence. J Gen Virol 2012; 93(Pt 10): 2063-2075.

30 Lawrence TM, Hudacek AW, de Zoete MR, Flavell RA, Schnell MJ. Rabies virus is recognized by the NLRP3 inflammasome and activates interleukin- 1 beta release in murine dendritic cells. J Virol 2013; 87: 5848-5857.

31 Ray NB, Ewalt LC, Lodmell DL. Rabies virus replication in primary murine bone marrow macrophages and in human and murine macrophage-like cell lines: implications for viral persistence. J Virol 1995; 69: 764-772.

32 Nakamichi K, Inoue S, Takasaki T, Morimoto K, Kurane I. Rabies virus stimulates nitric oxide production and CXC chemokine ligand 10 expression in macrophages through activation of extracellular signal-regulated kinases 1 and 2. J Virol 2004; 78: $9376-9388$.
33 Turner GS, Ballard R. Interaction of mouse peritoneal macrophages with fixed rabies virus in vivo and in vitro. J Gen Virol 1976; 30: 223-231.

34 Brouckaert G, Kalai M, Krysko DV, Saelens X, Vercammen D, Ndlovu MN et al. Phagocytosis of necrotic cells by macrophages is phosphatidylserine dependent and does not induce inflammatory cytokine production. Mol Biol Cell 2004; 15: 1089-1100.

35 Ubol S, Kasisith J, Pitidhammabhorn D, Tepsumethanol V. Screening of proapoptotic genes upregulated in an experimental street rabies virus-infected neonatal mouse brain. Microbiol Immunol 2005; 49: 423-431.

36 Rutherford M, Jackson AC. Neuronal apoptosis in immunodeficient mice infected with the challenge virus standard strain of rabies virus by intracerebral inoculation. J Neurovirol 2004; 10: 409-413.

37 Theerasurakarn S, Ubol S. Apoptosis induction in brain during the fixed strain of rabies virus infection correlates with onset and severity of illness. J Neurovirol 1998; 4: 407-414.

38 Jackson AC. Apoptosis in experimental rabies in bax-deficient mice. Acta Neuropathol 1999; 98: 288-294.

39 Beckham JD, Tuttle KD, Tyler KL. Caspase-3 activation is required for reovirusinduced encephalitis in vivo. J Neurovirol 2010; 16: 306-317.

40 Kojima D, Park CH, Satoh Y, Inoue S, Noguchi A, Oyamada T. Pathology of the spinal cord of C57BL/6J mice infected with rabies virus (CVS-11 strain). J Vet Med Sci 2009; 71: 319-324.

41 Yan X, Prosniak M, Curtis MT, Weiss ML, Faber M, Dietzschold B et al. Silver-haired bat rabies virus variant does not induce apoptosis in the brain of experimentally infected mice. J Neurovirol 2001; 7: 518-527.

42 Laothamatas J, Wacharapluesadee S, Lumlertdacha B, Ampawong S, Tepsumethanon V, Shuangshoti $S$ et al. Furious and paralytic rabies of canine origin: neuroimaging with virological and cytokine studies. J Neurovirol 2008; 14: 119-129.

43 Roy A, Phares TW, Koprowski H, Hooper DC. Failure to open the blood-brain barrier and deliver immune effectors to central nervous system tissues leads to the lethal outcome of silver-haired bat rabies virus infection. J Virol 2007; 81: 1110-1118.

44 Roy A, Hooper DC. Immune evasion by rabies viruses through the maintenance of blood-brain barrier integrity. J Neurovirol 2008; 14: 401-411.

45 Fehlner-Gardiner C, Nadin-Davis S, Armstrong J, Muldoon F, Bachmann P, Wandeler A. Era vaccine-derived cases of rabies in wildlife and domestic animals in Ontario, Canada, 1989-2004. J WildI Dis 2008; 44: 71-85.

46 van de Craen M, Vandenabeele P, Declercq W, Van den Brande I, Van Loo G, Molemans $\mathrm{F}$ et al. Characterization of seven murine caspase family members. FEBS Lett 1997; 403: 61-69.

47 Desmedt M, Rottiers P, Dooms H, Fiers W, Grooten J. Macrophages induce cellular immunity by activating Th1 cell responses and suppressing Th2 cell responses. J Immunol 1998; 160: 5300-5308.

48 Rosseels V, Naze F, De CS, Francart A, Kalai M, Van Gucht S. A non-invasive intranasal inoculation technique using isoflurane anesthesia to infect the brain of mice with rabies virus. J Virol Methods 2011; 173: 127-136.

49 Hayashi S, Lewis P, Pevny L, McMahon AP. Efficient gene modulation in mouse epiblast using a Sox2Cre transgenic mouse strain. Mech Dev 2002; 119(Suppl 1): S97-S101.

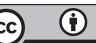

This work is licensed under a Creative Commons Attribution 4.0 International License. The images or other third party material in this article are included in the article's Creative Commons license, unless indicated otherwise in the credit line; if the material is not included under the Creative Commons license, users will need to obtain permission from the license holder to reproduce the material. To view a copy of this license, visit http://creativecommons.org/licenses/ by/4.0/

(c) The Author(s) 2017 